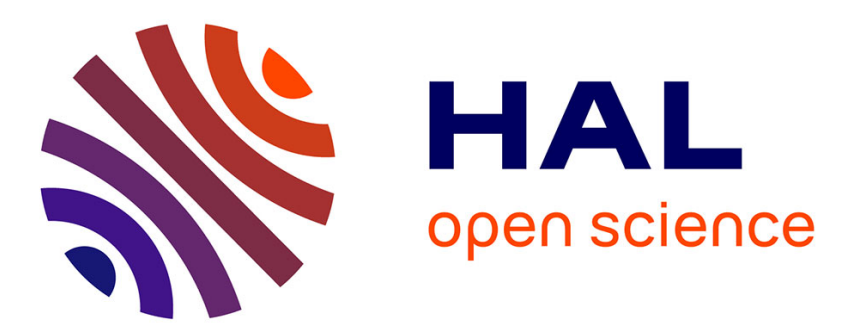

\title{
Accelerated aging of absorber coatings for CSP receivers under real high solar flux - Evolution of their optical properties
}

Reine Reoyo-Prats, Alex Carling Plaza, Olivier Faugeroux, Bernard Claudet, Audrey Soum-Glaude, Christina Hildebrandt, Yaniv Binyamin, Alina Agüero, Tobias Meissner

\section{To cite this version:}

Reine Reoyo-Prats, Alex Carling Plaza, Olivier Faugeroux, Bernard Claudet, Audrey Soum-Glaude, et al.. Accelerated aging of absorber coatings for CSP receivers under real high solar flux - Evolution of their optical properties. Solar Energy Materials and Solar Cells, 2019, 193, pp.92-100. 10.1016/j.solmat.2018.12.030 . hal-03463290

\section{HAL Id: hal-03463290 \\ https://hal-univ-perp.archives-ouvertes.fr/hal-03463290}

Submitted on 13 Dec 2021

HAL is a multi-disciplinary open access archive for the deposit and dissemination of scientific research documents, whether they are published or not. The documents may come from teaching and research institutions in France or abroad, or from public or private research centers.
L'archive ouverte pluridisciplinaire HAL, est destinée au dépôt et à la diffusion de documents scientifiques de niveau recherche, publiés ou non, émanant des établissements d'enseignement et de recherche français ou étrangers, des laboratoires publics ou privés. 


\title{
Accelerated aging of absorber coatings for CSP receivers under real high solar flux - Evolution of their optical properties
}

https://doi.org/10.1016/j.solmat.2018.12.030

Journal: Solar energy materials and solar cells, accepted 17 December 2018

\author{
Authors \\ Reine REOYO-PRATS ${ }^{a, *}$, Alex CARLING PLAZA ${ }^{a}$, Olivier FAUGEROUX ${ }^{a, *}$, Bernard CLAUDET ${ }^{a}$, Audrey \\ SOUM-GLAUDE ${ }^{a}$, Christina HILDEBRANDT ${ }^{b}$, Yaniv BINYAMIN ${ }^{c}$, Alina AGÜERO ${ }^{d}$, Tobias MEIßNER \\ a Procédés, Matériaux et Energie Solaire (PROMES), UPR 8521. \\ Tecnosud-Rambla de laThermodynamique, 66100 Perpignan, France / 7 rue du Four Solaire, 66120 \\ Font-Romeu Odeillo Via, France. \\ ${ }^{b}$ Fraunhofer-Institut für Solare Energiesysteme ISE \\ Heidenhofstr. 2, 79110 Freiburg, Germany \\ ${ }^{c}$ Brightsource Industries \\ 11 Kiryat Mada St., Amot bldg \#6, P.O. Box 45220, Har Hotzvim, Jerusalem, 91450 Israel \\ ${ }^{d}$ Instituto Nacional de Tecnica Aerospacial (INTA) \\ Ctra. de Ajalvir Km 4, 28850 Torrejón de Ardoz, Spain \\ e DECHEMA-Forschungsinstitut, High Temperature Materials \\ Theodor-Heuss-Allee 25, 60486 Frankfurt am Main, Germany \\ * Corresponding authors: reine.reoyo@promes.cnrs.fr (R. Reoyo-Prats), \\ olivier.faugeroux@promes.cnrs.fr (O.Faugeroux)
}

\begin{abstract}
The use of durable high solar absorptance receivers is a key element in a CSP plant project. In this article, different receiver materials are studied: four alloy substrates (T91, T22, VM12, Inconel 617) combined with four new absorber coatings, operable in solar towers with molten salts or steam as heat transfer fluids, and a classic Pyromark ${ }^{\circledR}$ paint considered as a reference. In order to test the durability of the coatings, 200 solar accelerated aging cycles were applied on the samples, using a concentrated solar facility (named SAAF). The cycles were defined so as to apply realistic high solar flux and temperature on the front side of the samples, and with high cooling and heating rates reproducing the fast variation of solar irradiation due to cloudy weather and subsequent thermal shocks. The optical characteristics of the coatings were measured at the beginning and at regular intervals during the aging procedure. Different behaviors of the coatings were observed depending on the substrate, before any aging cycle. After this first aging campaign, some evolutions were observed on the solar absorptance or thermal emittance, depending on the substrate and the coating. Nevertheless, the degradations noticed are not significant enough to conclude about the durability of the coatings.
\end{abstract}

\section{Keywords}

Accelerated aging

CSP receiver absorber coatings

Optical characterization

Solar furnace

\section{Symbols and abbreviations}

c: speed of light in vacuum, c $=3.00 \cdot 10^{8} \mathrm{~m} \cdot \mathrm{s}^{-1}$

$\mathrm{h}$ : Planck's constant, $\mathrm{h}=6.63 \cdot 10^{-34} \mathrm{~J} . \mathrm{s}$

$\mathrm{k}$ : Boltzmann's constant, $\mathrm{k}=1.38 \cdot 10^{-23} \mathrm{~J} . \mathrm{K}^{-1}$

$\sigma$ : Stefan Boltzmann's universal physical constant, $\sigma=5 \cdot 67 \cdot 10^{-8} \mathrm{~W} \cdot \mathrm{m}^{-2} \cdot \mathrm{K}^{-4}$

NIR region: Near Infrared region

Mid IR region: Mid Infrared region

DNI: Direct Normal Irradiance 


\section{Introduction}

The increase in the share of renewable energy on the energy market needs the use of all the available sources (sun, wind, biomass, etc.) and the development of different kinds of devices to exploit them. Among them, the concentrating solar power (CSP) plants combine several advantages. The most noteworthy is the possibility to store the generated heat in order to produce electricity when the sun irradiance is not available (at night, or during cloudy days). Due to its big growth potential, there has been a lot of studies for the development of these plants and their performances during the past decades [1], [2], [3].

Nowadays, these CSP plants allow for a large scale production, with a power supply of around 400MW for one of the biggest plants so far, Ivanpah in California [4]. This kind of plant represents an important financial investment, so they are expected to work during 25 years at least. It is important to keep a high level of performance to maintain the cost-efficiency of the installation. This is the main purpose of the European project Raiselife started in 2016 [5]. A consortium of laboratories and industrial companies from Europe (France, Germany, Italy, Spain) and south of Mediterranean (Israel, Morocco) are working together to study the lifetime of the different components of a CSP plant, and to suggest new materials.

In a solar tower, the receiver is one of the key elements to consider when looking at the lifetime of the plant: it is the intermediate component between the concentrated solar flux and the heat transfer fluid. It can receive a flux of about $850 \mathrm{~kW} / \mathrm{m}^{2}$, and it can reach an outlet temperature higher than $600^{\circ} \mathrm{C}$ for a liquid receiver and $700^{\circ} \mathrm{C}$ for a gas receiver [6].The receiver suffers from the alternation of sun irradiance between day and night and the high variations of flux due to fast clouds. All these stresses can affect its efficiency, and decrease the amount of heat transmitted to the fluid. Anticipating the evolution of its performance is a major issue to manage the economic efficiency of the plant and to plan the technical maintenance [7].

In this study, four alloy substrates and five coatings with high solar absorptance (four new coatings and a classic one) are investigated under aggressive aging cycles generated by concentrated solar irradiance. These materials are described in section 2. Their optical performance is evaluated several times during the aging process using measurement devices detailed in section 3 . Section 4 presents the Solar Accelerated Aging Facility (SAAF) used to apply the cycles, which was initially developed for a previous study [8], as well as the definition of the aging cycles. In this work, 200 cycles are applied on the samples. The objective is to observe the evolution of the optical characteristics and compare the different coatings. The results of the aging campaign and the discussion are detailed in section 5 .

\section{Materials tested and corresponding CSP plants}

Solar tower receivers collect the concentrated solar flux and transfer the heat to a fluid in order to produce electricity (Figure 1). Depending on the fluid and the temperature conditions of the generator, different kinds of substrates are used. In this study, we consider four standard kinds of substrates used in the solar tower receivers: T22 (2\% Cr), T91 (9\% Cr) and VM12 (12\% Cr) steel alloys, and Inconel 617 super alloy $(44 \% \mathrm{Ni}-20 \% \mathrm{Cr})$. T22, T91 and Inconel 617 can be used in solar receiver steam generators. T91 and Inconel 617 can be used for molten salt receivers. VM12 is considered to replace T91 in the future. 


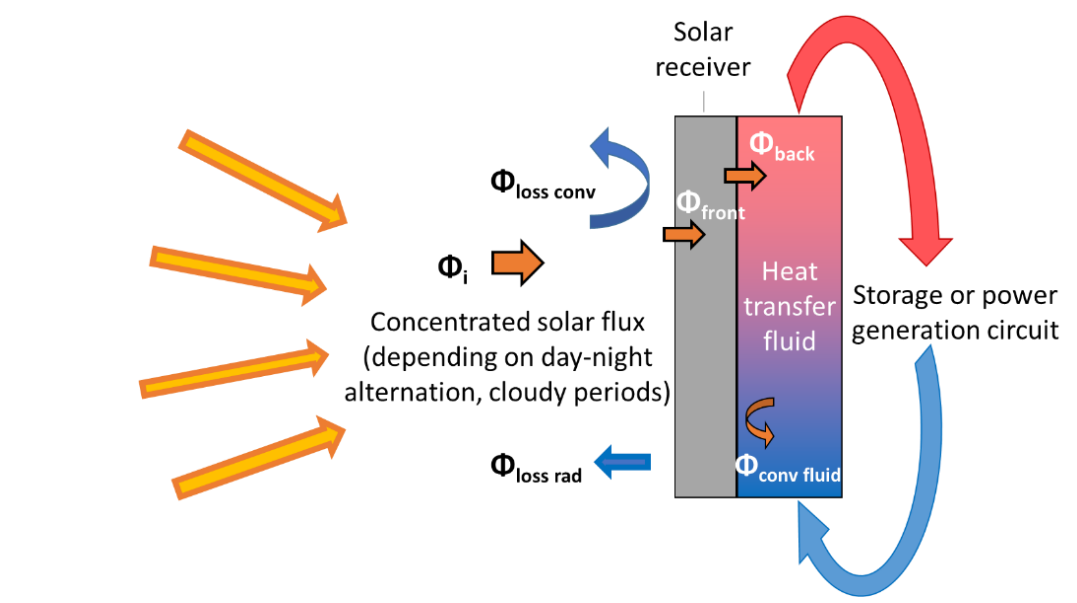

Figure 1 : Solar receiver, heat transfer from concentrated flux to the heat transfer fluid

In order to improve the global efficiency of steam and molten salt tower receivers, the operating temperature of the coating, its initial solar efficiency and its durability have to be increased. To this end, new high temperature solar receiver coatings are being developed during the Raiselife project by the consortium members:

$>$ a ceramic paint consisting of a primer and absorbing layer with black pigments, developed by BSII (referred to as Coating A);

$>$ a slurry deposited diffusion bond coating based on Al intermetallics, developed by INTA, with the ceramic absorbing coating A on top (referred to as Coating B). This protective layer is introduced to prevent the sample from hot oxidation;

$>$ a solar selective thin multilayered coating deposited by magnetron sputtering, developed by Fraunhofer, applied on a polished substrate (Coating C);

$>$ a multi-metallic diffusion coating based on chromium and manganese applied with the powder pack cementation process, developed by Dechema (Coating D).

Coatings $A, C$ and $D$ are applied on the four substrates. Coating B is only applied on T22, T91 and VM12 substrates.

To this day, Pyromark $^{\circledR} 2500$ is the most classically used absorber coating for high temperature solar receivers. A T91 sample has been coated with this black paint in accordance with the most recent protocol [9].The evolution of the new coatings after the aging tests is compared to the evolution of this one, considered as a reference.

\section{Aging characterization}

\subsection{Aging criteria: focus on optical characteristics}

The receiver is planned to withstand intense conditions. On one hand, its mechanical properties have to stay resilient enough to avoid a failure of the component, which would lead to an expensive replacement.

On the other hand, its optical and thermo-physical characteristics have to remain stable to keep the CSP plant efficiency at a cost-effective level. A decrease of the solar absorptance implies high reflective losses. In a thermal model developed by X. Li et al. [10], for a $100 \mathrm{kWt}$ molten salt receiver, it appears that a decrease of the absorptance from 0.9 to 0.1 leads to a decrease of the receiver efficiency from $90.04 \%$ to $58.93 \%$. So it is crucial to study the aging behavior of the coating absorptance, to ensure the CSP performance over the years. Moreover, even if the radiative losses are not as significant as reflective losses at these high temperatures [11], a good selective coating can make a great difference in the global efficiency in some cases [12].

In this study, the solar absorptance, the thermal emittance and the optical efficiency are considered. 


\subsection{Measuring devices and method for the characterization}

The solar weighted absorptance, the thermal emittance and the optical efficiency are calculated thanks to the measurement of the spectral hemispherical reflectance from $280 \mathrm{~nm}$ to $16000 \mathrm{~nm}$. This section presents the spectrophotometers used for the measurement, the global characteristics obtained, and a brief study of the repeatability of the results.

\subsubsection{Description of the devices: Perkin Elmer and SOC100}

The spectral hemispherical reflectance $R(\lambda)$ is measured with two spectrophotometers available at PROMES-CNRS, Odeillo, France.

In the UV - Visible - NIR region, a Perkin Elmer Lambda 950 is used. It measures the normal hemispherical spectral reflectance at room temperature between 250 and $2500 \mathrm{~nm}$, with $10 \mathrm{~nm}$ steps, with a $150 \mathrm{~mm}$ integrating sphere coated with Spectralon diffuse reflective coating, and an incidence angle of $8^{\circ}$ (this value being the closest possible to the normal incidence when using the Perkin Elmer Lambda 950).

In the Mid IR region, a SOC100-HDR reflectometer from Surface Optics Corporation, associated with a Thermo-electron Nicolet 6700 FTIR is used. The hemispherical directional reflectance is measured between 1500 and $25000 \mathrm{~nm}$ with an incidence angle of $8^{\circ}$ (again, the closest value to the normal incidence when using the Soc100-HDR).

The hemispherical reflectance of the five coatings applied on T91 substrate is shown as an example in Figure 2. All the coatings have a low reflectance level at short wavelengths (under $10 \%$ in the visible region $400-800 \mathrm{~nm}$ ), and thus a high absorptance level in this region (above 90\%). It appears that coatings A and B have a similar profile. Indeed, the top coating is the same in both cases (coating A). Coating $B$ just has an additional interlayer between the substrate and the ceramic paint. The Pyromark ${ }^{\circledR}$ coating has a similar profile too, but its reflectance is lower in the infrared region. Coating $C$ is the only selective coating. It reaches a high reflectance (so a low emittance, below 20\%) in the infrared region, which allows the decrease of radiative thermal losses. Coating $D$ has a higher reflectance than the other coatings in the visible region (so a lower absorptance), but presents an interesting reflectance in the infrared region, above $20 \%$ (so, an emittance below $80 \%$ ).

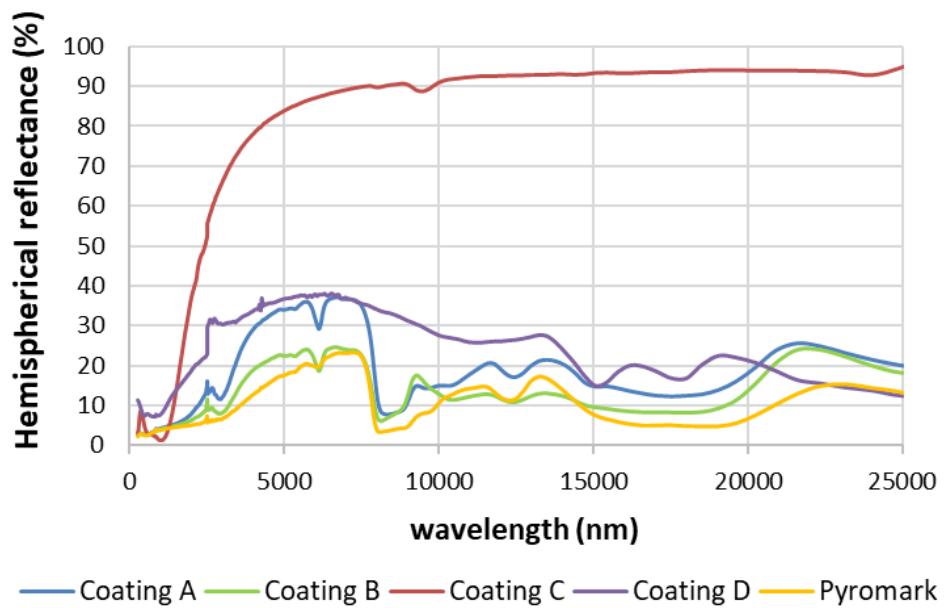

Figure 2: Hemispherical spectral reflectance $R(\lambda)$ measured for 5 coatings on T91 substrate

\subsubsection{Calculation of the main optical characteristics}

\section{Solar absorptance}

The near-normal hemispherical solar-weighted absorptance $\alpha_{s}$ is the ratio between the absorbed solar radiation (considering the reflection measured in the half sphere) and the incident solar radiation from the near-normal $\left(8^{\circ}\right)$ direction relative to the surface. It is calculated using the spectral 
hemispherical reflectance measurement $R(\lambda)$ and the ASTM G173-03 reference spectrum for solar direct normal irradiance $G_{\text {sol }}(\lambda)$ at an air mass (AM) of 1.5 , between $\lambda_{1}=280 \mathrm{~nm} ; \lambda_{2}=2500 \mathrm{~nm}$ (eq 1 ).

$$
\alpha_{s}=\frac{\int_{\lambda 1}^{\lambda 2}[1-R(\lambda)] \cdot G_{s o l}(\lambda) \cdot d \lambda}{\int_{\lambda 1}^{\lambda 2} G_{s o l}(\lambda) \cdot d \lambda}
$$

In real conditions, the solar radiation reaches the receiver with different angles depending on the plant, on the distance of the heliostats, on the time of day, etc. Moreover, the temperature receiver is around $650^{\circ} \mathrm{C}$ (see Table 1). In laboratory, in order to control the evolution of the optical characteristics, the hemispherical directional reflectance between 280 and $2500 \mathrm{~nm}$ is measured at room temperature considering a near-normal incident angle. Indeed, several experiments reported in [9], carried on Inconel, SS304 and cold-rolled steel samples coated with Pyromark ${ }^{\circledR} 2500$ corroborate this approximation. On one hand, the solar weighted near-normal absorptance measured with a temperature of $29^{\circ} \mathrm{C}$ and $600^{\circ} \mathrm{C}$ is respectively 0.965 and 0.967 . On another hand, the spectral directional absorptance is measured considering different incident angles of irradiance between $10^{\circ}$ and $80^{\circ}$. The spectral absorptance decreases slightly when increasing this angle from $60^{\circ}$, and decreases more significantly at $80^{\circ}$. But, at $10^{\circ}$ and $40^{\circ}$ the values are similar.

\section{Thermal emittance}

The near-normal hemispherical thermal emittance $\varepsilon_{t h}(T)$ at temperature $T(K)$ is calculated (eq2) considering Kirchoff's law: the spectral directional emittance is equal to the spectral directional absorptance. So we used the spectral hemispherical reflectance measurement $R(\lambda)$ in a UV - Visible Mid IR region between $\lambda_{1}=280 \mathrm{~nm}$ to $\lambda_{3}=16000 \mathrm{~nm}$, and the corresponding blackbody radiation spectrum $L_{B B}(\lambda, T)$ defined by Planck's law (eq3):

$$
\begin{gathered}
\varepsilon_{t h}(T)=\frac{\int_{\lambda 1}^{\lambda 3}[1-R(\lambda)] \cdot L_{B B}(\lambda, T) \cdot d \lambda}{\int_{\lambda 1}^{\lambda 3} L_{B B}(\lambda, T) \cdot d \lambda} \\
L_{B B}(\lambda, T)=\frac{2 \pi h c^{2}}{\lambda^{5} \cdot\left[\exp \left(\frac{h c}{\lambda k T}\right)-1\right]}
\end{gathered}
$$

where $\mathrm{c}, \mathrm{h}$ and $\mathrm{k}$ are the speed of light in vacuum, Planck's constant and Boltzmann's constant, respectively.

The wavelength region used is shortened to $280-16000 \mathrm{~nm}$, instead of the $250-25000$ region measured. The results are part of Raiselife project where other laboratories do the same kind of characterization on other samples, so the calculation was standardized among the consortium partners.

As well as the absorptance, the thermal emittance depends on the incidence angle of irradiance, and on the sample temperature. In this study, as for the absorptance, the reflectance between 280 and $16000 \mathrm{~nm}$ is measured at room temperature, with a near-normal incident angle $\left(8^{\circ}\right)$. Clifford K. Ho et al. [9] examined the impact of this parameters on the total hemispherical emittance. It appears that the total hemispherical emittance calculated with a normal spectral reflectance measurement of a Pyromark ${ }^{\circledast}$ sample at $26^{\circ} \mathrm{C}$ and $600^{\circ} \mathrm{C}$ are similar (slightly higher, about $1 \%$, for the calculation with the $600^{\circ} \mathrm{C}$ sample measurement). 
Moreover, concerning the incident angle, the ratio of total hemispherical emittance to normal hemispherical emittance varies between 0.9 and 1.1 for a normal hemispherical emittance between 0.25 and 0.9 (which corresponds to the values of the present study). In order to check this results with our samples, we did some measurements, with different incident angles between $8^{\circ}$ and $80^{\circ}$ : the spectral reflectance measured is similar between $8^{\circ}$ and $30^{\circ}$ and increases slightly with the increasing of the incident angle between 40 and $60^{\circ}$.

\section{Optical efficiency}

In order to determine the evolution of the coating efficiency with one global parameter, the coating optical efficiency is calculated (eq4). The power input takes into account the solar absorptance $\alpha_{s}$ and the concentrated solar flux $Q_{\text {sol }}\left(\mathrm{W} / \mathrm{m}^{2}\right)$ applied on the coating. The radiative losses take into account the thermal emittance $\varepsilon_{t h}(T)$ and the temperature of the coating $(T)$. The convective losses are neglected.

$$
\eta_{\text {coating }}\left(T, Q_{\text {sol }}\right)=\frac{\alpha_{s} \cdot Q_{\text {sol }}-\varepsilon_{\text {th }} \cdot \sigma \cdot T^{4}}{Q_{\text {sol }}}
$$

where $\sigma$ is the Stefan Boltzmann's constant.

Considering the level of flux and coating temperature at stake, it is possible to compare the effect of the variation of absorptance and emittance on the optical efficiency. For example, we take into account an incident flux $Q_{\text {sol }}$ of $500 \mathrm{~kW} \cdot \mathrm{m}^{-2}$ and a coating temperature of $650^{\circ} \mathrm{C}$ (eq. 5).

$$
\frac{\partial \eta_{\text {coating }}}{\partial \alpha_{s}}=1 ; \frac{\partial \eta_{\text {coating }}}{\partial \varepsilon_{\text {th }}}=\frac{-\sigma \cdot T^{4}}{Q_{\text {sol }}}=-0.082
$$

We observe that the optical efficiency is much more sensitive to a variation of the absorptance than the same variation of the emittance. In order to increase the efficiency by $1 \%$, it is possible to increase the solar absorptance by $1 \%$, or to decrease the thermal emittance by $1 / 0.082=12.2 \%$.

\subsubsection{Brief study of the repeatability of the results}

In order to study the evolution of the main optical characteristics, it is important to have an idea of the repeatability of the results. They may vary between two consecutive measurements, or between measurements done on different days (for a same sample, which is supposed to be unchanged). The uncertainties can be caused by various factors: intrinsic uncertainties of the measuring equipment, human factor, change of weather (temperature, humidity), etc.

We have selected 12 samples composed of different substrates (Inconel 617, T22, VM12) and different coatings (A, B, C, D) in order to test the devices on samples with different optical behaviors. Some of them were used in the aging facility and the others were kept in their original state. We have measured the hemispherical reflectance 3 consecutive times for the samples which were in an aging phase (the reflectance is measured every 65 cycles approximately). On another hand, we have measured the reflectance of the non-aged samples 5 times, on different days. These samples have not been subjected to any aging cycle, so it is possible to compare the measurements taken at different moments. Figure 3 shows that, most of the time, the optical efficiency, calculated from the measurements, varies by 0.1 or $0.2 \%$. But, for some samples, the maximal difference between two measurements can reach $0.7 \%$. For sample $n^{\circ} 5$, the optical efficiency varies from 92.6 to $93.3 \%$.

Thereafter, we will keep this order of magnitude in mind to examine and not misinterpret the evolution of the optical characteristics after the aging cycles. 


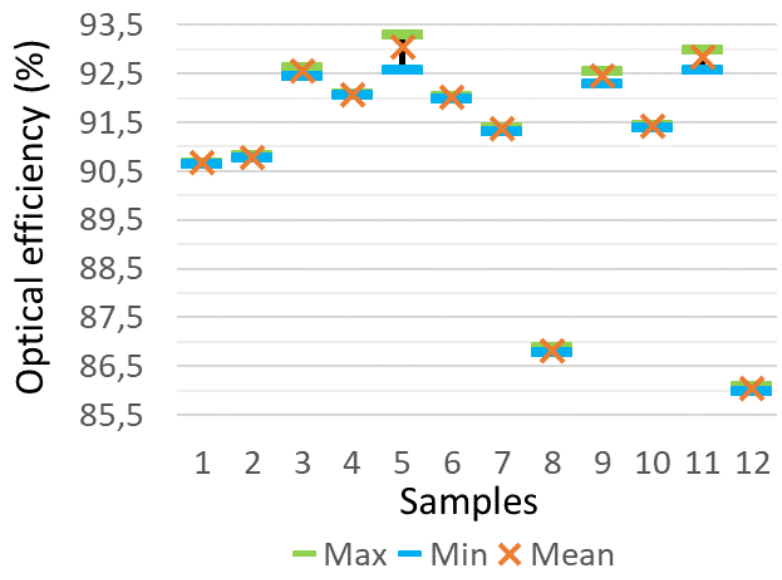

Figure 3 : Optical efficiency of some samples for the study of repeatability

Besides repeatability, the accuracy of the results is being investigated in the framework of the Raiselife project. A Round Robin Test is ongoing between several members of the consortium. The conclusions of this investigation will be interesting to know the real performance of the coatings with more precision.

\section{Accelerated aging tests}

The accelerated aging tests have been carried out on a solar concentrating device, the SAAF. The facility is presented in section 4.1. In section 4.2 , the aging cycles are described.

\subsection{Use of SAAF - Solar Accelerated Aging Facility}

A Solar Accelerated Aging Facility (Figure 4) has been designed at PROMES-CNRS laboratory, in Odeillo (France) based on the facility used for a previous study [13]. The measurement and the control of the solar flux received by the sample were improved by Y. Lalau et al.[14].

For this study, the facility uses a $1.5 \mathrm{~m}$ in diameter parabola, with a concentrating factor of approximately 15000 . A heliostat reflects the sun's rays on this parabola. A kaleidoscope, made of polished aluminum, is positioned at the focal point of the parabola to homogenize the solar flux. It is $60 \mathrm{~mm}$ long, and has a square aperture of $20 \times 20 \mathrm{~mm}$. The sample to be tested is installed at the outlet of the kaleidoscope and receives a homogenized flux.

The flux is controlled by shutters which can be closed/opened depending on the flux instruction and the DNI (Direct Normal Irradiance, W. $\mathrm{m}^{-2}$ ). The relationship between the DNI, the opening ratio of the shutters, and the flux on the outlet of the kaleidoscope (Figure 5) was determined when the bench has been set up, thanks to a calorimetry device. The shutter can be fully opened in 0.7 second, so fast flux cycles can be applied on the samples.

The temperature on the sample is measured by an Optris G5H CF4 pyrometer, considering the emissivity of the sample. The spectral sensitivity of the pyrometer is $5.2 \mu \mathrm{m}$, so it is considered solar blind. In order to control the temperature on the front surface of the sample exposed to the high solar flux, an air cooling device is used on the back of the sample. The air flow is adjusted to reach the set point temperature.

Moreover, a thermocouple is put on the side of the sample in order to follow the temperature evolution on an additional point. 

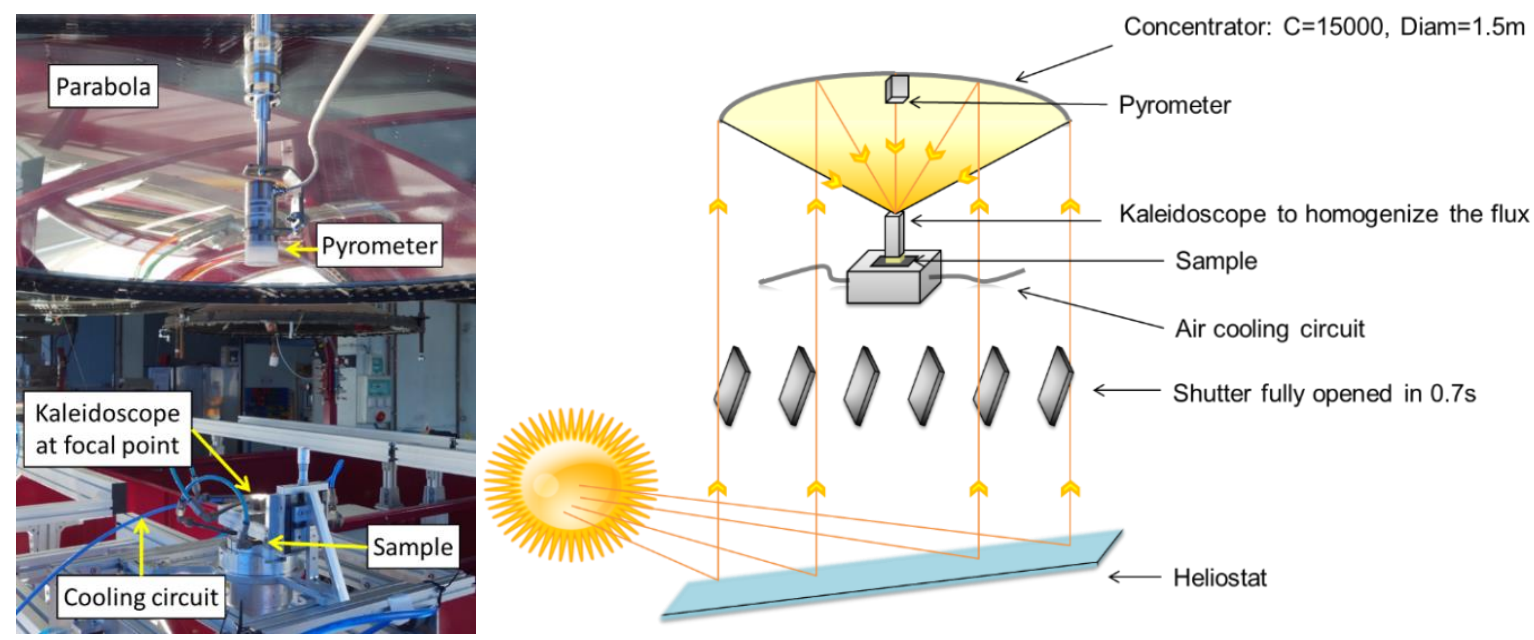

Figure 4 : Solar Accelerated Aging Facility a) Picture of the parabola and the sample implantation - b) Diagram of the whole device.

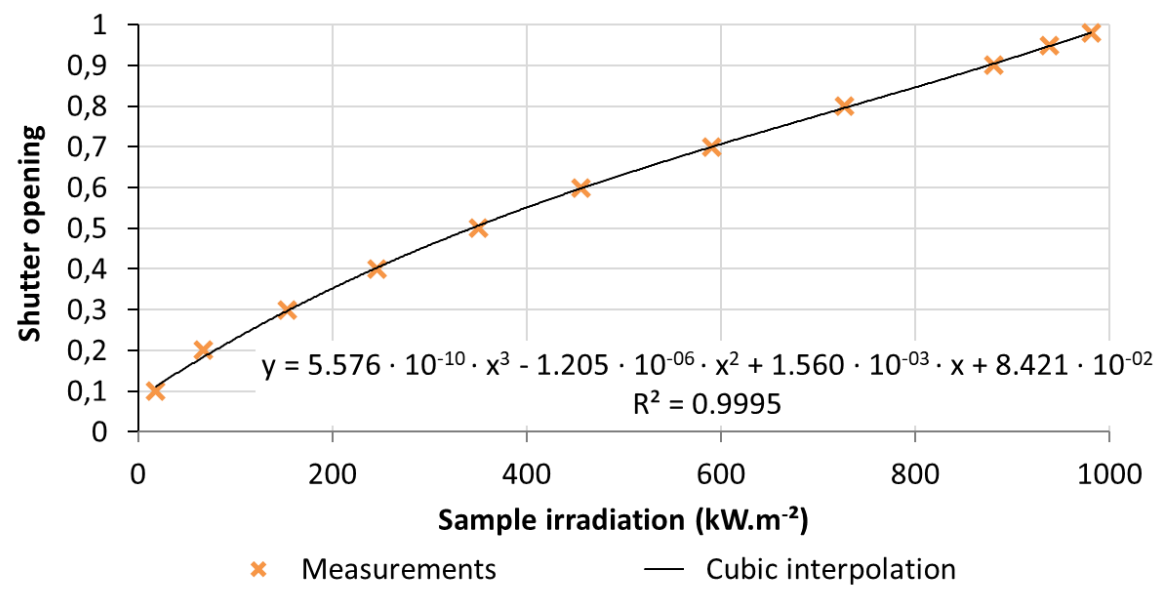

Figure 5 : Shutter opening of the device depending on sample irradiation DNI

\subsection{Determination of the cycles}

The objective of an accelerated aging approach is to reproduce the evolution of the coating over the years in a much shorter period, from a few hours to a few weeks, in order to predict and anticipate the degradation of the performances. To this end, it is necessary to expose the coating to fast, but non unrealistic, degradation mechanisms. The main difficulty consists in determining a relevant aging procedure which could cause damage close to the real in situ damages. For example, according to the experience of CSP plant managers, it is conceivable to visually observe a slight discoloration of the coating, or a corrosion default, but a strong and fast delamination should warn of a non-plausible degradation mechanism.

We have used the conclusions of A. Boubault et al.[13]: a sensitive study has been carried out to investigate the parameters (mean irradiance, amplitude of the irradiance, period of the cycles) which maximize the thermal stress factors (like the temperature of the coating, its spatial gradients, its temporal gradients). Square-shaped irradiance cycles are chosen. The period is as short as possible in order to do a high number of cycles in a short duration, but it is long enough to reach the permanent regime. For each kind of substrate, this period is experimentally determined, as well as the necessary cooling air flow on the rear face. These parameters are adjusted in order to reach a maximal setpoint temperature for a maximal given flux, corresponding to the operating condition of the CSP plant (Table 1). For example, coatings on T22 are supposed to work in steam generation plants, with a flux of 
$600 \mathrm{~kW} / \mathrm{m}^{2}$ and a temperature of $600^{\circ} \mathrm{C}$. The temperature response (cooling rate on front face) depends on the substrate and on the coating (example of aging cycle in Figure 6).

\begin{tabular}{|c|c|c|c|c|c|}
\hline & & & & \\
\hline & & T91 & $\mathrm{T} 22$ & VM12 & Inconel \\
\hline \multicolumn{2}{|c|}{ Flux $\min / \max \left(\mathrm{kW} / \mathrm{m}^{2}\right)$} & $250 / 500$ & $250 / 600$ & $250 / 500$ & $250 / 750$ \\
\hline \multicolumn{2}{|c|}{$\begin{array}{l}\text { Duration of the two phases } \\
\text { cycles: } \\
\text { low flux/high flux (s) }\end{array}$} & $60 / 200$ & $60 / 200$ & $60 / 100$ & $30 / 40$ \\
\hline \multicolumn{2}{|c|}{ Max. temperature $\left({ }^{\circ} \mathrm{C}\right)$} & 650 & 600 & 650 & 700 \\
\hline \multirow{4}{*}{$\begin{array}{l}\text { Approximate flow } \\
\text { of cooling air on } \\
\text { rear face }(\mathrm{g} / \mathrm{s})\end{array}$} & Coating $\mathrm{A}$ & 0.8 & 2.1 & 1.3 & 6.8 \\
\hline & Coating B & 0.7 & 2.5 & 1.1 & No sample \\
\hline & Coating $\mathrm{C}$ & 0 & 1.7 & 0.8 & 6.7 \\
\hline & Coating D & 0.5 & 1.6 & 0.2 & 7.1 \\
\hline \multirow{4}{*}{$\begin{array}{l}\text { Max. cooling rate } \\
\text { on front face }\left({ }^{\circ} \mathrm{C} / \mathrm{s}\right)\end{array}$} & Coating $\mathrm{A}$ & -40 & -50 & -30 & -90 \\
\hline & Coating B & -30 & -50 & -30 & No sample \\
\hline & Coating C & -20 & -30 & -20 & -100 \\
\hline & Coating D & -30 & -40 & -20 & -120 \\
\hline
\end{tabular}

Table 1: Aging protocol for the high flux solar cycles, for each substrate

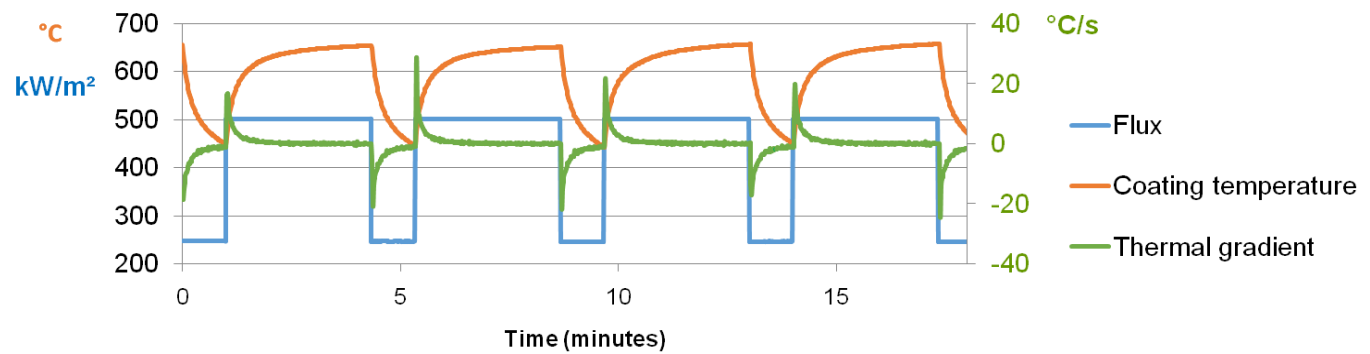

Figure 6 : Aging cycles applied on T91 samples with coating D: concentrated solar flux $\left(\mathrm{kW} \cdot \mathrm{m}^{-2}\right)$, temperature of the coating $\left({ }^{\circ} \mathrm{C}\right)$, speed variation of the temperature $\left({ }^{\circ} \mathrm{C} . \mathrm{s}^{-1}\right)$

A more aggressive cycle is tested on one sample, T91 with coating $A$, in order to push the limits of the nominal operating conditions. We applied a maximal flux of $700 \mathrm{~kW} / \mathrm{m}^{2}$ and a maximal temperature of $800^{\circ} \mathrm{C}$ (Figure 7) instead of $500 \mathrm{~kW} / \mathrm{m}^{2}$ and $650^{\circ} \mathrm{C}$.

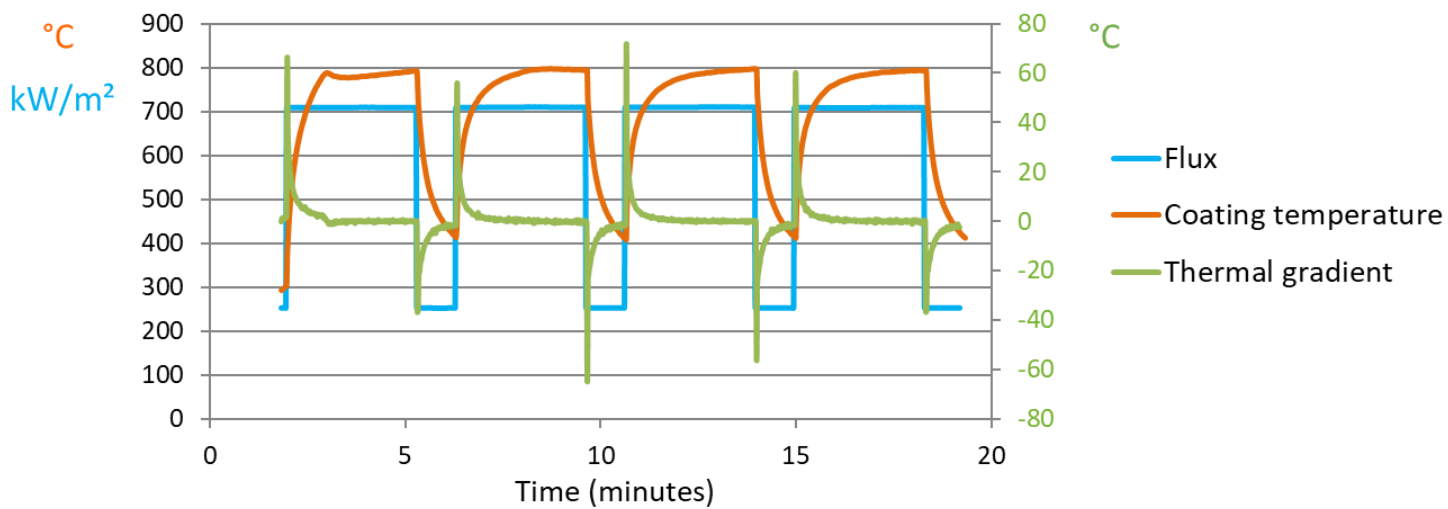

Figure 7 : Aggressive aging cycles applied on T91 sample with coating A. 
These kinds of cycles have to be compared with real conditions in a CSP plant.

The DNI is measured and recorded each second, in Odeillo, France. It can be very fluctuating on a cloudy day (Figure 8.a). A focus on one minute (Figure 8.b) shows that the speed variation (W. $\mathrm{m}^{-}$ ${ }^{2} . \mathrm{s}^{-1}$ ) of the irradiance received by the mirrors can fluctuate from 300 to $-300 \mathrm{~W} \cdot \mathrm{m}^{-2} \cdot \mathrm{s}^{-1}$ very quickly.

On a CSP plant, the concentrating factor can reach 1000 . In this case, this cloudy situation could imply a variation of $300 \mathrm{~kW} \cdot \mathrm{m}^{-2} \cdot \mathrm{s}^{-1}$ approximately on the receiver.
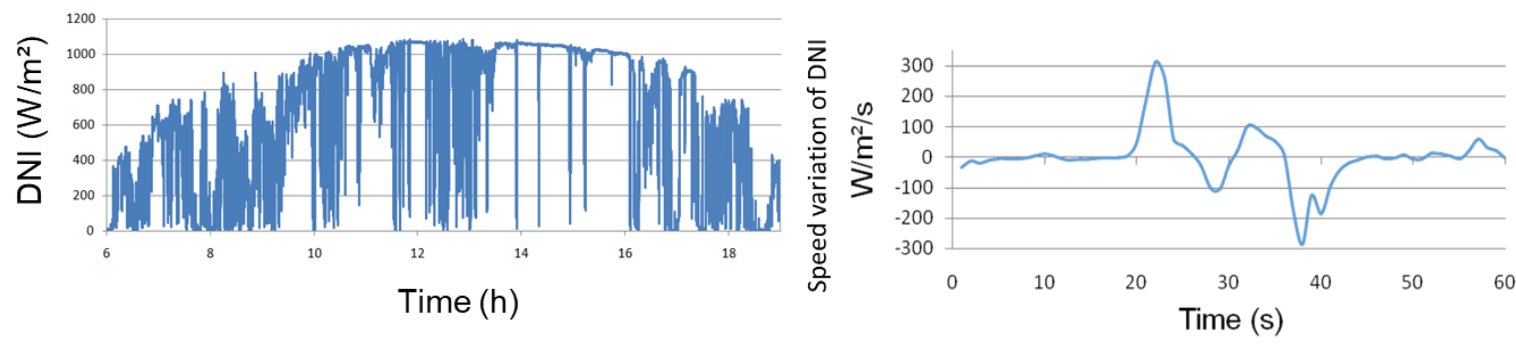

Figure 8 : Example on a cloudy day: 2 April 2017 a) DNI (W.m ${ }^{-2}$ ) over one day, b) speed variation (W. $\left.\mathrm{m}^{-2} . \mathrm{s}^{-1}\right)$ over one minute

On another hand, a study on 30 consecutive days (January - February 2017) shows that, considering the real DNI recorded at Odeillo, and considering a concentrating factor of 1000, the flux variation could exceed, on a receiver, $420 \mathrm{~kW} \cdot \mathrm{m}^{-2} \cdot \mathrm{s}^{-1}$ once, and $250 \mathrm{~kW} \cdot \mathrm{m} \cdot{ }^{-2} \cdot \mathrm{s}^{-1}$ six times in this period.

So, the square shaped cycles described above are aggressive enough to maximize some thermal stress factors, because of their intense variation and short periods, but correspond to realistic conditions.

\section{Results and Discussion}

The characteristics of the coatings before any aging cycle are different depending on the substrate on which they are deposited. This is illustrated in section 5.1.

In section 5.2, we present the results of the aging solar cycles.

The studies above show that the aging cycles chosen are realistic but the issue of the relevance of the protocol is discussed in section 5.3 in the light of the results obtained. Furthermore, some additional aging strategies are considered.

\subsection{Initial performance of the different substrate-coating combinations}

We compare all the combinations of substrate/new coatings in terms of solar absorptance, thermal emittance and optical efficiency, before any aging cycle (except the combination Inconel+Coating B which has not been tested). Moreover, in order to compare the results with a reference, the classic Pyromark ${ }^{\circledR}$ coating has been applied on T91 substrate. Figure 9 shows that these characteristics are similar but not exactly the same for a given coating, depending on the substrate on which it is deposited. For example, the absorptance of coating C varies from 93.4 on T22 substrate to $94.5 \%$ on VM12 substrate. It seems that the adhesion on T22 substrate is more difficult. Also, the thermal emittance of coating A varies from 76.9 (on T91 and VM12 substrates) to $92.9 \%$ (on Inconel substrate).

Coating $D$ is a particular case, because the coating has been improved between the manufacture of the VM12/T91 samples and the T22/Inconel samples. 


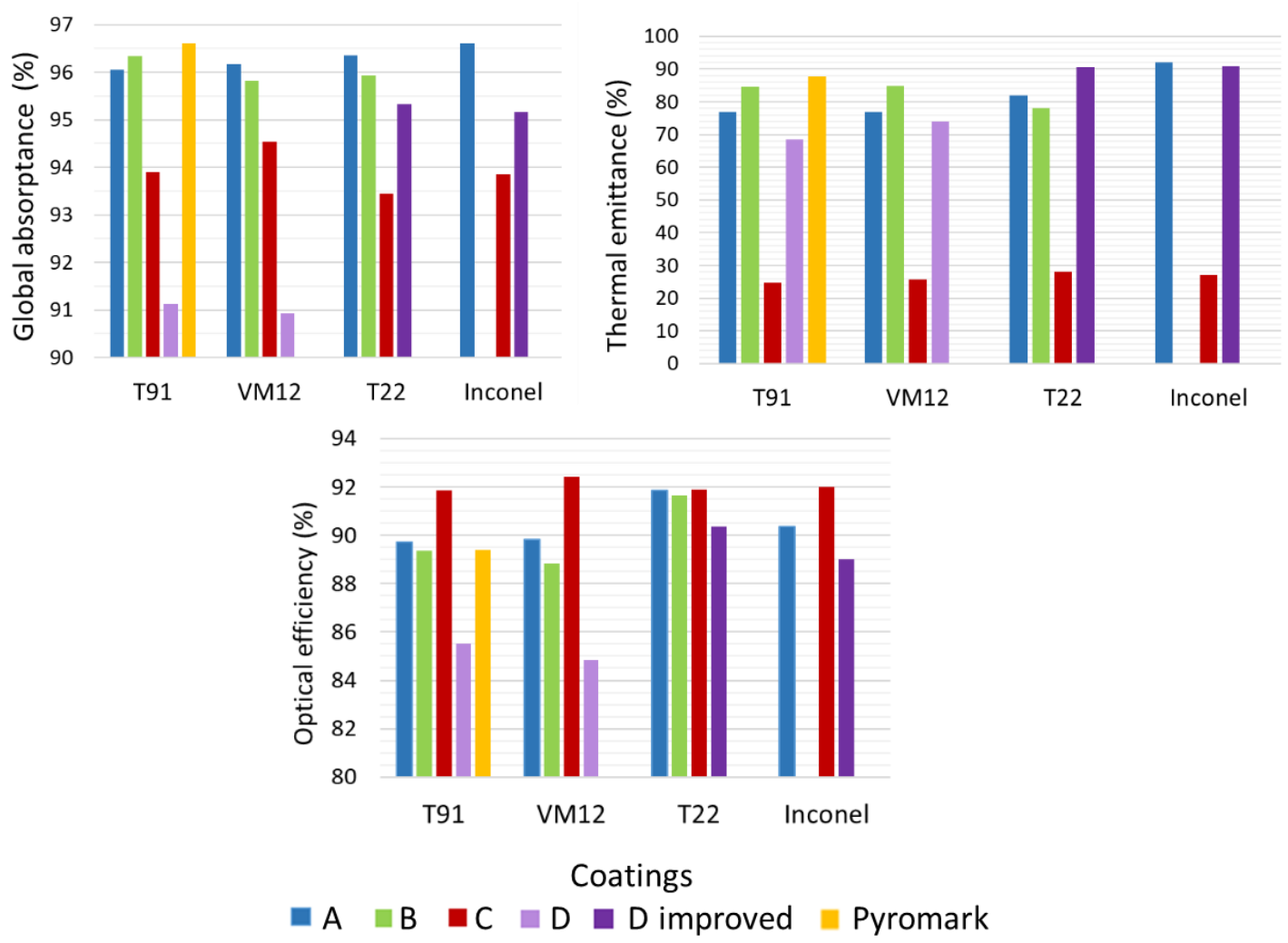

Figure 9 : a) Solar absorptance (\%), b) Thermal emittance (\%), c) Optical efficiency (\%) of all the samples before aging tests

Overall, coating A has, most of the time, the highest solar absorptance, above $96 \%$ (Figure 9a). However, the selective coating $C$ has the highest optical efficiency (Figure 9c) due to a good absorptance (around $94 \%$ ) combined with a very low emittance, below $30 \%$ (Figure 9b). The Pyromark ${ }^{\circledR}$ coating applied on T91 substrate, considered as the reference, has the highest solar absorptance (96.6\%), but also the highest thermal emittance (87.7\%), leading to lower optical efficiency.

\subsection{Results of the solar aging campaign}

For each kind of sample (each coating applied on three or four different substrates, and Pyromark $^{\circledast}$ applied on one substrate, 16 samples in total), 200 cycles have been completed. For some samples and some characteristics, there has not been any change. The figures below (Figure 10 to 14) show the cases where an evolution is considered as significant (see 3.2.3).

\section{T91 samples}

On T91 samples, with the first kind of cycle (Table 1), no significant evolution of the coating absorptance is measured. The variations are too small to be considered as a real improvement or degradation of the property.

The thermal emittance has increased for only one sample, with coating $D$ (Figure 10). It is a continuous increase over the aging procedure: from $68.4 \%$ before any aging cycle, to $73.7 \%, 74.2 \%$, $75.5 \%$ after 60,130 , and 200 aging cycles. This means that the radiative heat losses increase with the aging. Nevertheless, the deterioration of this characteristic does not seem to influence critically the global performance: the optical efficiency decreases just slightly from 85.5 to $84.9 \%$. 


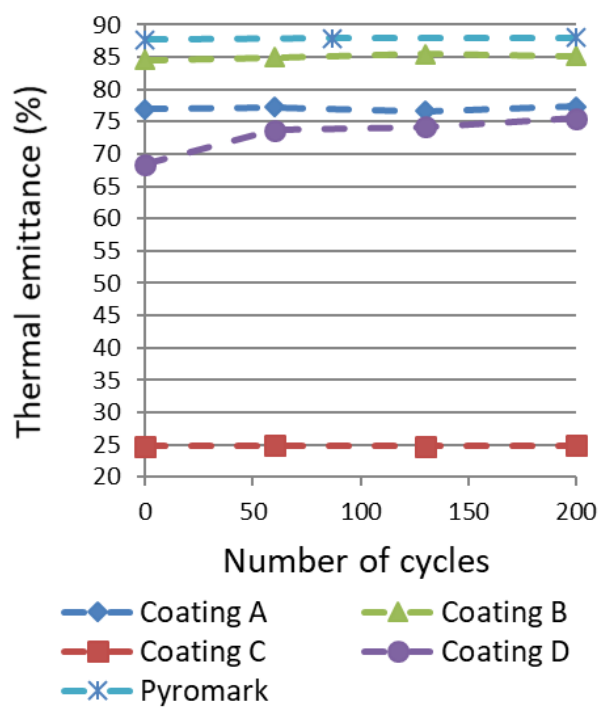

Figure 10 : Thermal emittance (\%) of T91 samples with 5 coatings after high flux accelerated aging tests

With the second kind of cycle, more aggressive (Figure 7), the thermal emittance seems to be more deteriorated, from 73.6 to $77.4 \%$ (Figure 11). But, thanks to the stability of the solar absorptance $(96.2+/-0.1 \%)$, the optical efficiency decreases just slightly, from 88.3 to $87.8 \%$. Moreover, the initial characteristics are not exactly the same, even if the substrate and the coating are the same. So, it is difficult to associate this modest decrease with the aggressive cycling.
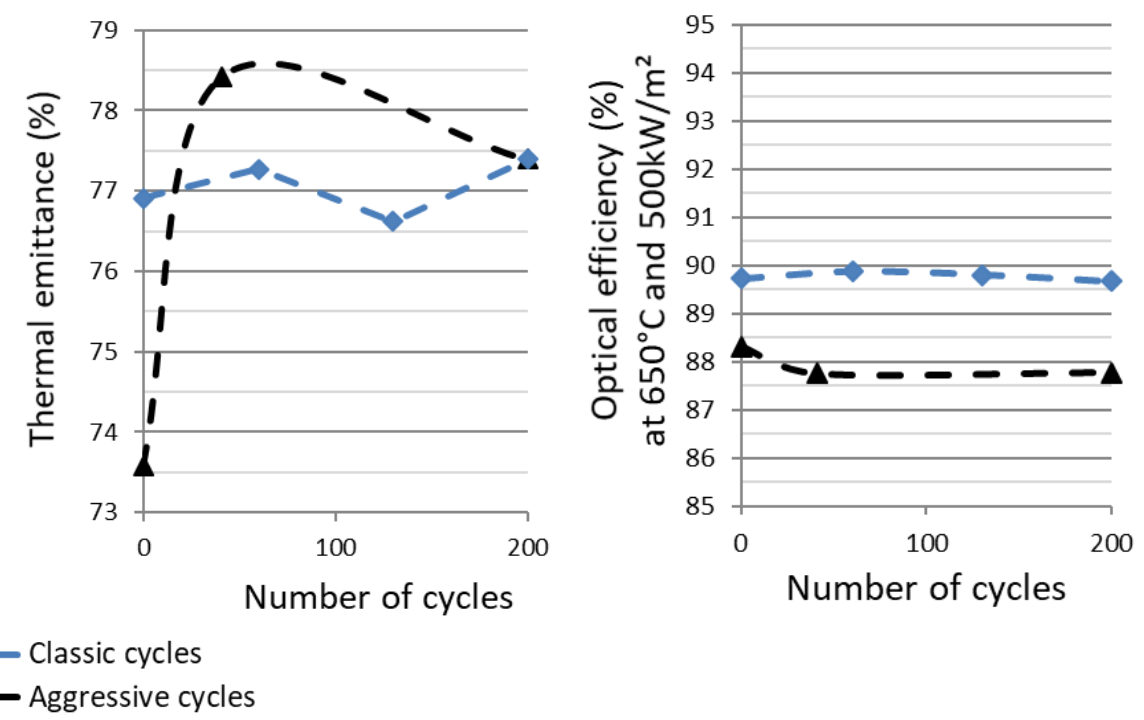

Figure 11 : Optical characteristics (\%) of T91 samples with coating A after different accelerated aging tests - a) thermal emittance, b) optical efficiency

\section{T22 samples}

On T22 samples (Figure 12), coating $C$ is the most striking. Its thermal emittance does not evolve, but its solar weighted absorptance increases from $93.4 \%$ to $94.2,94.6,94.8 \%$ after 60,130 , 200 cycles. Due to this increase, the optical efficiency is improved from $91.9 \%$ to $93.2 \%$.

Meanwhile, the absorptance of coatings $A, B$ and $D$ remains stable, but their thermal emittance decreases: from 82.0 to $79.6 \%$ on coating $A$, from 78.1 to $75.7 \%$ on coating $B$, and from 90.5 to $89.6 \%$ on coating $\mathrm{D}$. These variations allow the samples to decrease their radiative losses, but they are not 
significant enough to impact significantly their optical efficiency: a slight variation of 0.1 or $0.3 \%$ is calculated.
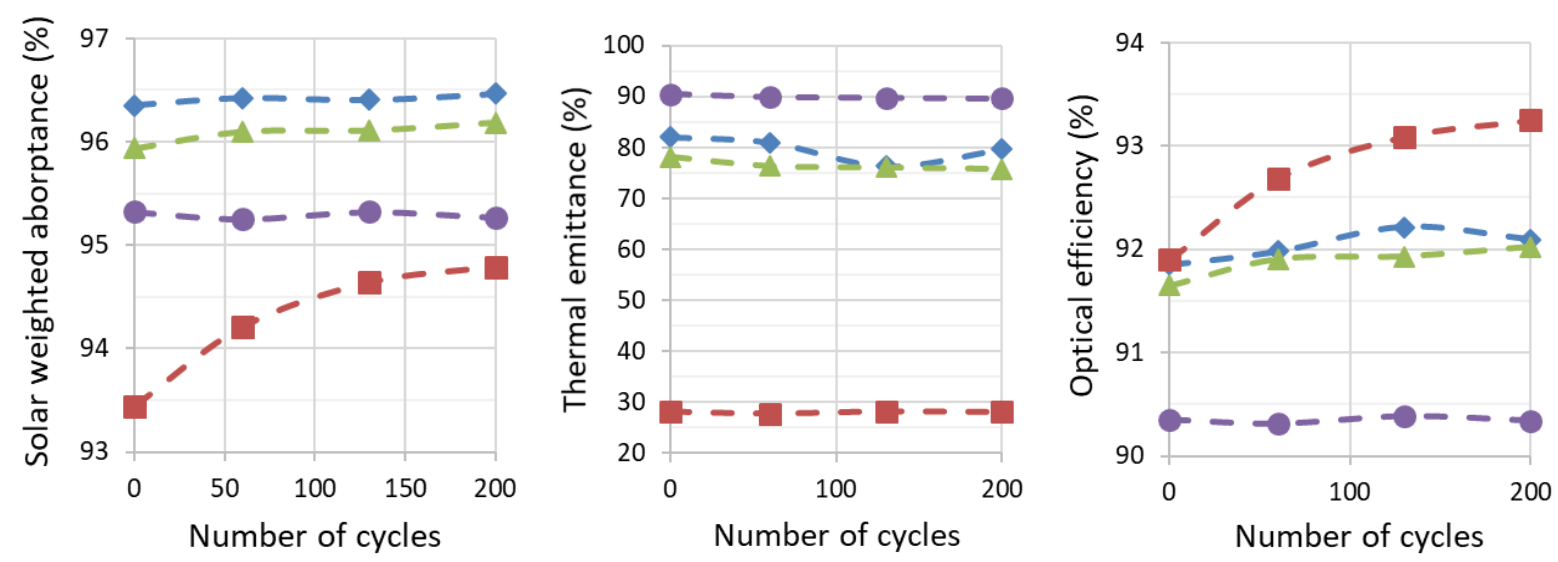

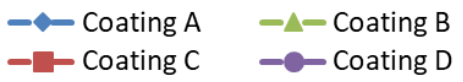

Figure 12: Optical characteristics (\%) of T22 samples with 4 coatings after high flux accelerated aging tests - a) solar weighted absorptance, b) thermal emittance, c) optical efficiency

\section{VM12 samples}

On VM12 samples (Figure 13), coating B has the most relevant evolution. Its thermal emittance increases from 84.9 to $86.1 \%$, which means there are more radiative losses. But the solar weighted absorptance has been improved, from 95.8 to $97.1 \%$ after 60 cycles, and then, has been stabilized until 200 cycles. Overall, the optical efficiency increases from 88.8 to $89.8 \%$.

Despite the fact that coating $B$ is very similar to coating $A$, with an additional protective layer between the substrate and the top coating, coating $A$ does not present the same behavior. Its thermal emittance, solar absorptance and optical efficiency remain stable at, respectively, $(77.0+/-0.2) \%,(96.2$ $+/-0.1) \%$ and $(89.9+/-0.1) \%$.

Similarly, coatings $C$ and $D$ properties remain stable, with an optical efficiency of, respectively, $(92.3+/-0.2) \%$ and $(84.6+/-0.2) \%$.
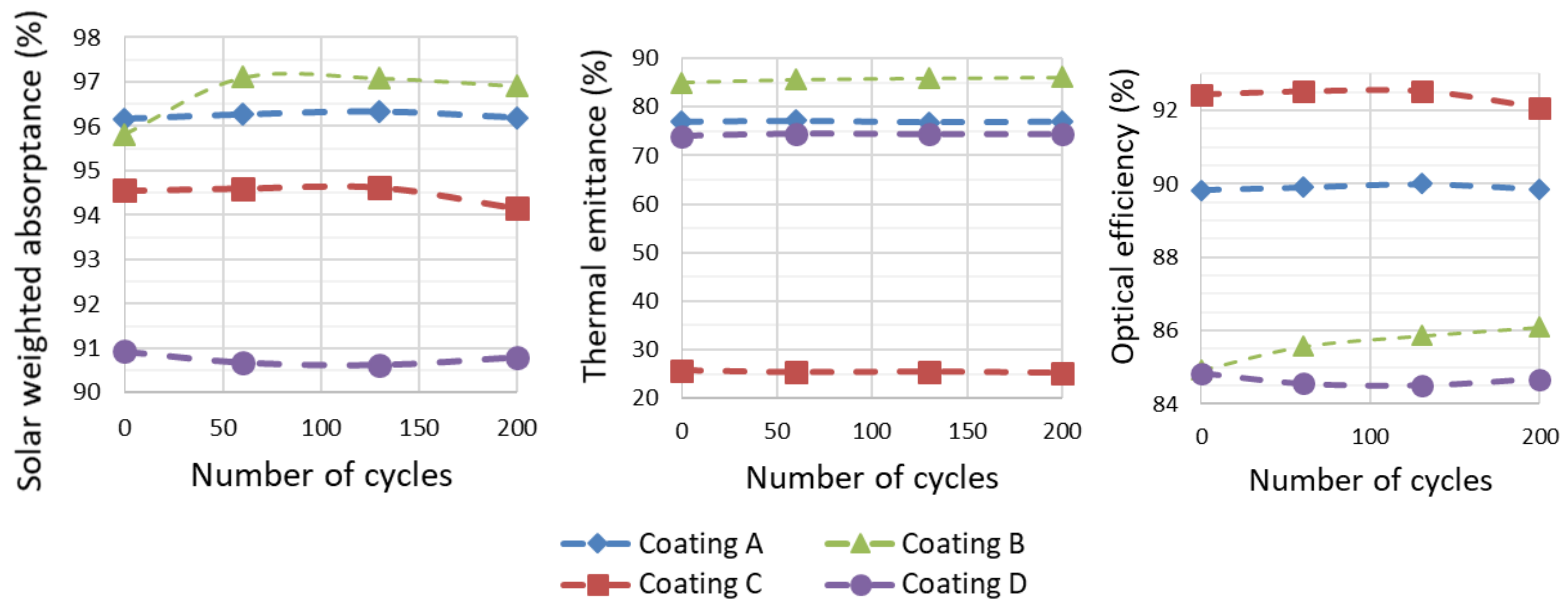

Figure 13: Optical characteristics (\%) of VM12 samples with 4 coatings after high flux accelerated aging tests 


\section{Inconel 617 samples}

On Inconel samples (Figure 14), the 3 coatings $A, C$ and D remain stable, with an optical efficiency of, respectively, $(90.5+/-0.2) \%,(91.9+/-0.6) \%$ and $(89.2+/-0.2) \%$.

Inconel aging cycles are shorter than the others (70 seconds per cycle), so we have been able to continue the aging further, up to 500 cycles for coating $\mathrm{A}$. We notice a decline of coating $\mathrm{C}$ solar absorptance after 200 cycles, but then, the value increases again after 300 cycles. This fluctuation can be due to an error of measurement. Overall, the additional cycles do not affect the performance of the coatings.

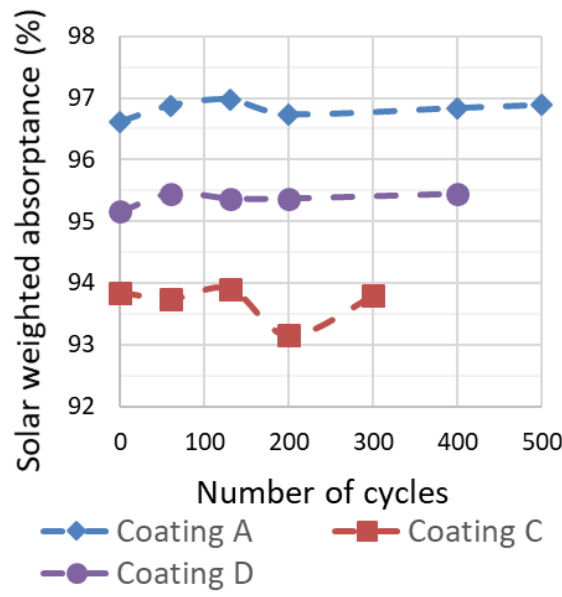

Figure 14: Optical characteristics (\%) of Inconel 617 samples with 3 coatings, A, C, D, after high flux accelerated aging tests

\subsection{Discussion}

After 200 cycles, no unreal or unexpected degradation has been observed so far, even with the classic Pyromark ${ }^{\circledast}$ coating. So the cycles applied are not to be considered as too aggressive, regarding the optical properties, despite their quick variation of flux and temperature. The global optical efficiency seems to remain stable, for all coatings, on all substrates. We even noticed an improvement in some cases: the T22 substrate with coating $C$, and the VM12 substrate with coating $B$. This could be due to a curing phenomenon emerging at these levels of flux and temperature.

Nevertheless, a degradation of the characteristics was expected, since real receivers on solar tower show signs of deterioration after a few years [15].

One explanation can be the need to carry out more cycles to cause a real aging of the coating. This assumption has been tested on Inconel samples. The samples with coatings A, C, D have suffered respectively 500, 300 and 400 aging cycles, without any significant deterioration. A round of 100 additional cycles is currently ongoing on some other samples, with other substrates.

The total duration of the experiments can also be an important factor to increase in order to observe deterioration. The aging strategy presented in 4.2 is based on the speed variation of the incident flux (square shaped signal) and the speed variation of the coating temperature. The cycles are the shortest possible so we can apply a maximal number of cycles in a short period. So, depending on the substrate (see the periods in Table 1), the 200 cycles are achieved in 4, 9 or 14 hours (distributed over 3 days). An increase of the period, maintaining a steady-state at the maximal temperature for a longer duration, could lead to a degradation of the coating.

Finally, it is possible to amplify the thermal stress factors, increasing the maximal flux applied on the samples and the maximal temperature reached on the coatings. Indeed, pushing the testing conditions beyond the real working conditions of the receiver can appear necessary to truly accelerate the aging of the materials. One test has been conducted so far, on a T91+coating A sample, without any relevant evolution. More experiments are currently ongoing to test more aggressive strategies. Again, it will be important to check that no unrealistic damages are caused during the experiments. 


\section{Conclusions}

Fast solar cycles under concentrated solar flux were applied to different coatings deposited on different substrates. The objective was to simulate quick changes of solar input on the receiver due to cloudy weather. The cycles were defined in order to maximize the thermal stress factors during the shortest period possible. The objective was to accelerate the aging, without causing any unexpected deterioration, in order to anticipate the degradation of the coating on the plant over time.

After 200 aging cycles, no significant degradation has been observed. This can be due to an insufficient number of cycles. An additional round of aging is currently on going, until 300 cycles, on some samples. The application of more aggressive cycles is also planned (higher flux and higher temperature). Another reason can be the short duration of the tests. Increasing the time during which the coating is at the maximal temperature could be another strategy to test.

In order to correlate the results of the accelerated aging tests to the real durability of the coatings, it would be interesting to compare the degradations observed thanks to the test facility on the Pyromark ${ }^{\circledR}$ paint reference after more aging cycles, and the real degradations of the same paint occurring in some CSP plant receivers after several years of service.

This work is based on the study of thermal stress factors on the degradation of the optical properties. In the future, it will be interesting to test some additional factors of aging like humidity and dust, which are obviously real elements on CSP plants, often located in desert regions. Also, it will be relevant to study some other criteria of aging evolution like thermophysical properties: the measurement of the coating conductivity and diffusivity evolution with aging could lead to a better understanding of the deterioration of the materials.

\section{Acknowledgements}

This project has received funding from the European Union's Horizon 2020 research and innovation program RAISELIFE under grant agreement No 686008. Some members of the consortium have been directly involved on the tasks about high solar absorptance receiver: Vallourec (France), DLR - DeutschesZentrumfürLuft- und Raumfahrt (Germany).

The new kaleidoscope has been designed by Roger Garcia and the whole set-up has been built and improved by Harold Thibault, from PROMES-CNRS.

This work was supported by the French "Investments for the future" program managed by the National Agency for Research, under contract ANR-10-EQPX-49-SOCRATE (Equipex SOCRATE). The authors thank the Promatsol department of PROMES-CNRS, led by Christophe Escape, for the optical measurement devices, and Emmanuel Guillot for his help in the improvement of the aging facility.

\section{References}

[1] D. Barlev, R. Vidu, P. Stroeve, Innovation in concentrated solar power, Sol. Energy Mater. Sol. Cells. 95 (2011) 2703-2725. doi:10.1016/j.solmat.2011.05.020.

[2] O. Behar, A. Khellaf, K. Mohammedi, A review of studies on central receiver solar thermal power plants, Renew. Sustain. Energy Rev. 23 (2013) 12-39. doi:10.1016/j.rser.2013.02.017.

[3] X. Xu, K. Vignarooban, B. Xu, K. Hsu, A.M. Kannan, Prospects and problems of concentrating solar power technologies for power generation in the desert regions, Renew. Sustain. Energy Rev. 53 (2016) 1106-1131. doi:10.1016/j.rser.2015.09.015.

[4] C.K. Ho, C.A. Sims, J.M. Christian, Evaluation of glare at the Ivanpah Solar Electric Generating System, 69 (2015) 1296-1305. doi:10.1016/j.egypro.2015.03.150.

[5] Raising the Lifetime of Functional Materials for Concentrated Solar Power Technology, (2016). 
www.raiselife.eu.

[6] C.K. Ho, B.D. Iverson, Review of high-temperature central receiver designs for concentrating solar power, Renew. Sustain. Energy Rev. 29 (2014) 835-846. doi:10.1016/j.rser.2013.08.099.

[7] A. Boubault, K.C. Ho, A. Hall, T.N. Lambert, A. Ambrosini, Durability of solar absorber coatings and their cost-effectiveness, Sol. Energy Mater. Sol. Cells. 166 (2017) 176-184. doi:10.1016/j.solmat.2017.03.010.

[8] A. Boubault, B. Claudet, O. Faugeroux, G. Olalde, Aging of solar absorber materials under highly concentrated solar fluxes, Sol. Energy Mater. Sol. Cells. 123 (2014) 211-219. doi:10.1016/j.solmat.2014.01.010.

[9] C.K. Ho, A.R. Mahoney, A. Ambrosini, M. Bencomo, A. Hall, T.N. Lambert, Characterization of Pyromark 2500 for high-temperature solar receivers, in: ASME 2012 6th Int. Conf. Energy Sustain., San Diego, CA, USA, 2012: pp. 1-10.

[10] X. Li, W. Kong, Z. Wang, C. Chang, F. Bai, Thermal model and thermodynamic performance of molten salt cavity receiver, Renew. Energy. 35 (2010) 981-988. doi:10.1016/j.renene.2009.11.017.

[11] M. López-herraiz, A. Bello Fernandez, N. Martinez, M. Gallas, Effect of the optical properties of the coating of a concentrated solar power central receiver on its thermal efficiency, Sol. Energy Mater. Sol. Cells. 159 (2017) 66-72. doi:10.1016/j.solmat.2016.08.031.

[12] D. V Bellas, E. Lidorikis, Solar Energy Materials and Solar Cells Design of high-temperature solarselective coatings for application in solar collectors, Sol. Energy Mater. Sol. Cells. 170 (2017) 102-113. doi:10.1016/j.solmat.2017.05.056.

[13] A. Boubault, B. Claudet, O. Faugeroux, G. Olalde, J.J. Serra, A numerical thermal approach to study the accelerated aging of a solar absorber material, Sol. Energy. 86 (2012) 3153-3167. doi:10.1016/j.solener.2012.08.007.

[14] Y. Lalau, O. Faugeroux, E. Guillot, D. Andre, M. Huger, A. Proust, T. Chotard, B. Claudet, Solar Energy Materials and Solar Cells IMPACT: A novel device for in-situ thermo-mechanical investigation of materials under concentrated sunlight, Sol. Energy Mater. Sol. Cells. 172 (2017) 59-65. doi:10.1016/j.solmat.2017.07.002.

[15] Sandia National Laboratories, Final Report on the Power Production Phase of the 10MWe Solar Thermal Central Receiver Pilot Plant, 1988. 